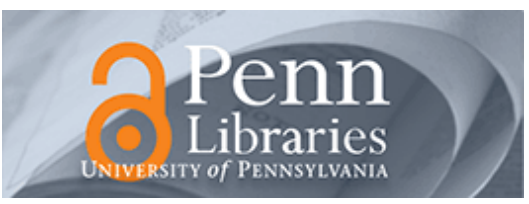

University of Pennsylvania ScholarlyCommons

March 2007

\title{
Employing community data to investigate social and structural dimensions of urban neighborhoods: An early childhood education example
}

\author{
Christine P. McWayne \\ New York University \\ Paul A. McDermott \\ University of Pennsylvania \\ John Fantuzzo \\ University of Pennsylvania, JOHNF@GSE.UPENN.EDU \\ Dennis P. Culhane \\ University of Pennsylvania, culhane@upenn.edu
}

Follow this and additional works at: https://repository.upenn.edu/spp_papers

\section{Recommended Citation}

McWayne, C. P., McDermott, P. A., Fantuzzo, J., \& Culhane, D. P. (2007). Employing community data to investigate social and structural dimensions of urban neighborhoods: An early childhood education example. Retrieved from https://repository.upenn.edu/spp_papers/66

Pre-print version. Published in American Journal of Community Psychology, Volume 39, Issues 1-2, March 2007, pages 47-60. The original publication is available at www.springerlink.com

Publisher URL: http://dx.doi.org/10.1007/s10464-007-9098-z

This paper is posted at ScholarlyCommons. https://repository.upenn.edu/spp_papers/66

For more information, please contact repository@pobox.upenn.edu. 


\title{
Employing community data to investigate social and structural dimensions of urban neighborhoods: An early childhood education example
}

\author{
Abstract \\ The present study sought to define neighborhood context by examining relationships among data from \\ city-level administrative databases at the level of the census block group. The present neighborhood \\ investigation included 1,801 block groups comprising a large, northeastern metropolitan area. Common \\ factor analyses and multistage, hierarchical cluster analyses yielded two dimensions (i.e., Social Stress, \\ Structural Danger) and two typologies (i.e., Racial Composition, Property Structure Composition) of \\ neighborhood context. Simultaneous multiple regression analyses revealed small but statistically \\ significant associations between neighborhood variables and academic outcomes for public school \\ kindergarten children.
}

\section{Keywords}

neighborhood context, administrative data, block group

\section{Comments}

Pre-print version. Published in American Journal of Community Psychology, Volume 39, Issues 1-2, March 2007, pages 47-60. The original publication is available at www.springerlink.com

Publisher URL: http://dx.doi.org/10.1007/s10464-007-9098-z 


\title{
Employing community data to investigate social and structural dimensions of urban neighborhoods: An early childhood education example
}

\author{
Christine M. McWayne - Paul A. McDermott • \\ John W. Fantuzzo $\cdot$ Dennis P. Culhane
}

(C) Springer Science+Business Media, LLC 2007

\begin{abstract}
The present study sought to define neighborhood context by examining relationships among data from city-level administrative databases at the level of the census block group. The present neighborhood investigation included 1,801 block groups comprising a large, northeastern metropolitan area. Common factor analyses and multistage, hierarchical cluster analyses yielded two dimensions (i.e., Social Stress, Structural Danger) and two typologies (i.e., Racial Composition, Property Structure Composition) of neighborhood context. Simultaneous multiple regression analyses revealed small but statistically significant associations between neighborhood variables and academic outcomes for public school kindergarten children.
\end{abstract}

Keywords Neighborhood context - Administrative data $\cdot$ Block group

\section{Introduction}

Developmental and ecological theories emphasize the transaction between larger contexts and children's development (Bronfenbrenner, 1992; Luthar, Cicchetti, \& Becker, 2000). Social scientists espousing these perspectives are increasingly considering the influence of

C. M. McWayne (ه)

Department of Applied Psychology, The Steinhardt School of Education, New York University, 239 Greene Street, New York, NY 10003-6674, USA

e-mail: cm106@nyu.edu

P. A. McDermott - J. W. Fantuzzo - D. P. Culhane University of Pennsylvania, Philadelphia, PA, USA factors within the neighborhood environment on child and youth outcomes. Theorists like Wilson (1987), Jencks and Mayer (1990), Furstenberg (1993), and Sampson, Morenoff, and Earls, (1999) have conceptualized mechanisms through which neighborhood context may impact individuals. Empirical studies testing aspects of these theories have indeed documented links between neighborhood characteristics and child and adolescent development (see Leventhal \& BrooksGunn, 2000 for a review).

It is clear that low-income children and their families experience different neighborhood influences than children whose families are not poor (Brooks-Gunn, Duncan, \& Aber, 1997). Poor families frequently reside in neighborhoods with high levels of community violence and crime (Farver, Natera, \& Frosch, 1999; Zill, Moore, Smith, Stief, \& Coiro, 1995) and inadequate housing conditions marked by health and safety hazards such as lack of heating, poor electrical wiring, exposed lead paint, and abandoned properties (Coulton, Korbin, $\& \mathrm{Su}, 1996$; Wilson, 1987). Urban poverty is intertwined with numerous other formidable neighborhood and family circumstances, such as high rates of teen birth, male unemployment, delinquency, truancy, and school dropout (Coulton, Korbin, Su, \& Chow, 1995) that can have import for young children's developmental outcomes (Leventhal \& Brooks-Gunn, 2000; Martinez, 2000). In fact, children growing up in affluent neighborhoods fare better in terms of intellectual markers, teenage motherhood, and school dropout, than children in low-income neighborhoods, even after family-level differences are controlled (Brooks-Gunn, Duncan, Klebanov, \& Sealand, 1993).

Ecological researchers have posited that information on multiple dimensions of both the physical and 
social aspects of neighborhood could prove useful for understanding underlying processes of neighborhood effects on child development (Duncan, Duncan, Okut, Strycker, \& Hix-Small, 2003; Leventhal \& BrooksGunn, 2003).

Research documenting relationships between aspects of neighborhood and early childhood educational outcomes has been relatively scant, in comparison with research investigating the impact on adolescent outcomes (Chase-Lansdale, Gordon, Brooks-Gunn, \& Klebanov, 1997). However, some studies have found relationships between neighborhood phenomena and early development. In the most comprehensive review to date on the effects of neighborhood residence on child and adolescent well-being, only five studies of neighborhood as it relates to measures of children's school readiness were identified (Leventhal \& Brooks-Gunn, 2000). This review revealed that in nationally representative samples of young children census variables such as neighborhood SES, rate of male joblessness, and ethnic heterogeneity of the neighborhood were associated with children's scores on measures of receptive vocabulary, kindergarten achievement and IQ, and children's internalizing and externalizing behaviors.

As with research involving young children and neighborhood influences, there exists a small but growing literature on single-city samples across the country, which yields inconsistent results (e.g., Chin \& Kameoka, 2002; Martinez, 2000; Spencer, McDermott, Burton, \& Kochman, 1997). In the majority of singlecity studies, no statistically significant relationships are demonstrated between various measures of neighborhood and youth outcomes. Researchers posit that perhaps effects are not found with single city samples due to insufficient variability among the participants' living conditions. Neighborhood researchers warn of this homogeneity problem when single-city samples are employed in studies of neighborhood (Duncan \& Raudenbush, 2001). In contrast, Spencer and associates (1997), examined neighborhood effects with a sample of 400 African American adolescents in Atlanta. Using both U.S. census tract-level information and information from "windshield surveys," Spencer and colleagues found that census level measures of neighborhood predicted adolescent achievement, but not behavior within this single city sample. However, no studies to date have employed a population-based examination in a single city, with a representative sample of young children.

Still further, questions have been raised about the appropriate measurement of neighborhood characteristics in existing studies, particularly as they might inform public policy. In examinations of neighborhood context, "neighborhood" has been defined in various ways-using census tract representations (e.g., Duncan \& Aber, 1997), by individuals' perceptions of their neighborhood (e.g., Martinez, 2000), and by systematic social observations (e.g., Sampson \& Raudenbush, 1999). There are problems, though, with these representations. Systematic social observations offer a promising and methodologically rigorous approach to the study of neighborhood and the mechanisms by which neighborhood affects development, but this method requires enormous time and personnel resources and, therefore, may not be particularly amenable to local policy-making efforts. Individual perceptions of neighborhood, though quite compelling as reflections of cultural experiences and social constructions of neighborhood (Burton, Price-Spratlen, \& Spencer, 1997), are notoriously unreliable (Duncan \& Raudenbush, 2001), and may not offer findings that are particularly relevant to local policies.

Perhaps because of these prohibitions, neighborhood has been most commonly represented using census tract variables collected during decennial U.S. Census surveys (Duncan \& Aber, 1997). Generally, when conducted with nationally representative samples, neighborhood factors have accounted for five percent of the variance in child outcomes, on average (Leventhal \& Brooks-Gunn, 2000). Brooks-Gunn and associates (1993) suggest that demographic and censusbased neighborhood variables are at best crude markers for the full range of contextual conditions that could buffer or exacerbate neighborhood effects on child development. With so many potentially influencing factors at the neighborhood level, disagreement exists regarding: (a) the appropriateness of census tract-level aggregation (which generally encompasses $1,500-8,000$ individuals in arbitrarily defined geographic polygons) as an adequate representation of neighborhood; (b) the sufficiency of census data to capture important variation in the social and physical environments of neighborhoods; and (c) the infrequent availability of data provided by the US Census ${ }^{1}$ (Burton et al., 1997; Hillier, Culhane, Smith, \& Tomlin, 2003; Leventhal \& Brooks-Gunn, 2000).

Neighborhood experts recommend that in order to more fully understand the complexity of neighborhood context, we must move beyond decennial census data. These researchers propose the use of administrative data to tap aspects of children's neighborhood

\footnotetext{
${ }^{1}$ Although the American Community Survey (ACS) will provide more frequent census data, this information will be limited at the census tract level (US Census Bureau, 2003).
} 
environment for several reasons. Variables such as the incidence of teen motherhood, child abuse and neglect rates, and crime and delinquency could prove to be important indicators of neighborhood phenomena related to child development (Leventhal \& BrooksGunn, 2000). Administrative data from public agencies provide researchers with the opportunity for creating more refined measures of neighborhood effects where they might exist, because administrative data record health, human service, education, public safety, and housing conditions at the individual household level on a continuous basis (Hillier \& Culhane, 2005). Such data can be aggregated at user-defined intervals and coincident with the enrollment of participants in research projects (Hillier \& Culhane, 2005). In addition, administrative data allow for the investigation of neighborhood at lower levels of aggregation (in contrast to the census tract) that might more closely approximate actual neighborhood phenomena (Burton et al., 1997; Hillier et al., 2003). Sampson and colleagues posit, "it may be that adults and children are located in distinct ecological niches within larger neighborhoods, suggesting the need to disaggregate analyses and study smaller ecological units such as block groups" (Sampson et al., 1999, p. 657). As well, research is needed that examines neighborhood in a multidimensional manner to account for the relatedness of multiple aspects of children's neighborhood environments. This is particularly true with respect to single cities, where multicollinearity poses a greater problem than in nationally representative samples (Duncan \& Raudenbush, 2001). In order for cities to translate findings from neighborhood research into policy, better methods for investigating city-level data are needed.

In response to these needs, the present study employed administrative data within a single-city to offer a population-based, multidimensional examination of neighborhood characteristics. The primary purpose of this study was to determine if reliable dimensions of neighborhood could be identified empirically. A secondary purpose was to examine if these dimensions would account for variance in the early academic outcomes of kindergarten children.

\section{Methods}

Block groups and quality of administrative data

In order to define neighborhood empirically, we explored the latent relationships among neighborhood variables at a lower level of aggregation than is commonly used-the census block group (which generally consists of 600-3,000 individuals compared to 1,500 to 8,000 of a census tract). One thousand, eight hundred one census block groups comprised the large, northeastern metropolitan area. According to the 2000 US National Census, this urban center had a total population of 1,517,550 residents, with $45 \%$ White residents, $43.2 \%$ Black or African American residents, $4.5 \%$ Asian residents, and $7.3 \%$ residents reported "multiple" or "other" race. Of the total population, $8.5 \%$ of residents identified Hispanic or Latino. The unemployment rate was reported to be $6.1 \%$ overall, and $26.8 \%$ of families reported an annual household income of less than $\$ 15,000$. Census data indicated that, overall, $30.1 \%$ of families with children under age 5 lived below the poverty level, and that there was disproportionate poverty for young Black children (where $64 \%$ of children under age 5 lived in families with household incomes below the poverty line).

Data for the 1,801 block groups were compiled by the Cartographic Modeling Lab (CML) at the University of Pennsylvania ${ }^{2}$ from a variety of municipal city agencies and the 2000 U.S. National Census. Municipal, administrative data were obtained from the Kids Integrated Database System (KIDS) and Neighborhood Information System (NIS) developed by the CML. NIS integrates and distributes information about physical properties and the "built environment," while KIDS contains human services data relating to children (Hillier \& Culhane, 2005). Municipal databases comprising these two systems included those housed within the Department of Human Services, Department of Public Health, Family Court, School District, Department of Licenses and Inspections, City Planning Commission, The Revenue Department, The Water Department, Gas Works, Board of Revision of Taxes, and the Office of Housing and Community Development.

Funding support has allowed the CML to employ sophisticated methods to ensure data quality and integrity. For example, as a part of the file creation process each of the participating agencies is instructed as to a set of standardized procedures for creating a unique identifier for each individual, facilitating the linkage of information across agencies. Cleaning each of the data sources prior to integrating data files facilitates the proper identification of distinct individuals as the files are combined. Assisting people in the file development at the respective sites and working with people who are familiar with their respective

\footnotetext{
${ }^{2}$ Specific information about the Cartographic Modeling Lab (CML) can be found at http://www.cml.upenn.edu.
} 
datasets in the matching and dataset creation process, helps to maintain data integrity. The CML, then, assumes responsibility for eliminating redundancies in the information and for the data integration. They employ complex computer algorithms to match individuals and services across systems over time, using the identifiers created. Data management includes reliability and validity auditing of data elements and the maintenance of data standards. Auditing routines have been developed to identify inconsistencies in client and service information, and a reporting framework is used to identify problems (Rothbard, Schinner, Hadley, \& Rovi, 1990). Audit routines contain the following components: (1) check of the correspondence between variable field specifications and data fields; entries outside the field are flagged and modified according to specifications; (2) check of consistency of client sociodemographic attributes with client IDs across data files; (3) recoding and compression of data to achieve efficient CPU processing and storage space; (4) check for duplicate records; (5) check for redundancy across data sources and data files by service type, provider, date, and client; and (6) use of a variety of statistical diagnostic routines on specific variables to establish if the data contained in each variable reflect its intended content. Algorithms linking individual clients across databases have been refined and tested extensively to assure that linked information is for the same client. Cases are dropped when questionable.

Although many limitations exist with these data, completion rates on relevant utilization and client characteristic elements have been over 90\% (Lurie, Popkin, Dysken, Moscovice, \& Finch, 1992). Chart reviews were done on a large percentage of the identified population to check data accuracy. Over $75 \%$ diagnostic agreement was found between the claims records and the client files.

\section{Child participants}

In addition to information regarding block group (neighborhood) characteristics, secondary data analyses were conducted with academic performance information from a sample of 5,026 public school kindergarten children in this large urban school district. ${ }^{3}$ All kindergarten classrooms in the school district operate for a full-day. This sample was chosen to be geographically and demographically representative of an entire cohort of children entering kindergarten in

\footnotetext{
${ }^{3}$ Child outcome information for this study was gathered as part of a larger system-wide evaluation (see Fantuzzo, Cohen, McDermott, Sekino, Childs, \& Weiss, 2004, submitted).
}

2000-2001. Participating schools were selected from each of the geographic regions (clusters) of the district, with the help of school district personnel. The number of schools sampled was determined by the size of the region, and then specific schools were chosen based on how representative they were of the ethnic and gender breakdown of kindergarten children within that region. In all, participants were drawn from 452 classrooms across 145 public elementary schools representing the 22 geographic areas of the district. An initial target sample of 6,000 children was drawn from the participating schools. However, due to missing data across one or both of the child performance indicators, $16 \%$ of the cases were deleted from further analyses; therefore, the final sample consisted of 5,026 kindergarten children. The demographics of the final sample closely approximated the demographics of the entire cohort of 15,343 public school kindergarten students (see Table 1). Within this population-based sample of kindergarten children, 1,789 out of the 1,801 block groups $(99 \%)$ were represented.

\section{Child outcome measures}

\section{Language arts skills}

The Language Arts Performance Assessment is a teacher evaluation of kindergarten children's language achievement. There are 18 items rated on a scale ranging from 1 (Improvement Needed) to 3 (Competent). These items included, for example, "understands print as a form of communication," "recognizes letters," "listens and responds to literature," and "identifies similarities and differences." Performance scores across all 18 items were averaged to create a composite score. These scores were then standardized using the entire cohort of kindergarten performance assessments $(N=15,343)$. Internal consistency for language arts was demonstrated to be high $(r=.93, p<.001)$. The language arts variable was also found to relate moderately to teacher observation of children's cognitive skills $(r=.36$, $p<.0001)$, with a subsample of Head Start children the spring prior to kindergarten entry $(N=240)$.

\section{Mathematics skills}

The Mathematics Performance Assessment is similar in format to the Language Arts assessment, and consists of 17 items. Items included, for example, "matches items one to one," "arranges objects according to size," "recognizes numerals," and "is aware of the concept of addition as joining sets." Performance 
Table 1 Sample demographics compared with population demographics for school district kindergarten children

\begin{tabular}{lll}
\hline $\begin{array}{l}\text { Demographic } \\
\text { Variable }\end{array}$ & $\begin{array}{l}\text { Sample } \\
(n=5,026)\end{array}$ & $\begin{array}{l}\text { Public School } \\
\text { District population } \\
(N=15,343)\end{array}$ \\
\hline $\begin{array}{l}\text { Gender } \\
\text { Male }\end{array}$ & $51 \%$ & $51 \%$ \\
Female & $49 \%$ & $49 \%$ \\
Race & $19 \%$ & $18 \%$ \\
White & $61 \%$ & $62 \%$ \\
African American & $16 \%$ & $15.3 \%$ \\
Hispanic & $3.8 \%$ & $4.5 \%$ \\
Asian & $0.2 \%$ & $66.0(S D=3.64)$ \\
Native American & $66.2(S D=3.87)$ & 6 \\
Mean age (in months) &
\end{tabular}

scores across all 17 items were averaged to create composite scores and were standardized similarly to the Language Arts assessments. Internal consistency was demonstrated $(r=.90, \quad p<.001)$. Children's mathematics skills in kindergarten were found to relate moderately with a classroom observation measure of cognitive skills $(r=.28, p<.001)$, with a subsample of Head Start children the spring prior to kindergarten entry $(N=240)$.

\section{Procedures}

Municipal administrative and U.S. Census data contained in NIS and KIDS were linked to identification-stripped individual child information by geocodes within the school district's database. These geocodes represented the census block group within which children reportedly resided when they registered for school at the beginning of the school year. Thus, these geocodes allowed the researchers to link child level outcome data from school district records to the same geographies as municipal records (i.e., census block groups). Neighborhood variables were based on information from the full population of block groups in the city of Philadelphia $(N=1,801)$. Counts of each particular individual neighborhood phenomenon (e.g., truant youths, teen births, row homes, etc) were aggregated from municipal records at the census block group level.

With respect to child level data, this study involved collection of two types: (a) kindergarten children's age, sex, race, and block-group level identification (geocode), and (b) performance assessments of children's emergent literacy and numeracy skills. Prior to the start of the school year, research team members and district officials met to draft a confidentiality agreement and data collection procedures. The enrollment database that included children's demographic information was obtained and linked to the integrated neighborhood data file. First, records from each respective database were matched according to child's block group and verified with child identification number and address from the school district file. Then, random checks of the linked records were conducted for $20 \%$ of the total sample, and the linkages were found to be $100 \%$ accurate. Lastly, teachers collected performance assessments across the kindergarten year as a part of their normal student evaluation process. At the end of the school year, this performance database was obtained and linked by matching school district identification numbers for each child. (Note: For purposes of this study, only the initial performance evaluations collected in November were examined.) Random checks were again performed to ensure accurate linkage, and $100 \%$ of cases were found to be correctly linked.

\section{Data analyses}

\section{Defining neighborhood dimensions}

Two different, yet complementary data reduction techniques were employed to define empirically neighborhood dimensions among city-level administrative and US Census data. Since no study to date has attempted to explore latent variable relations among administrative neighborhood data, we chose exploratory common factor analysis as one method. Multistage, hierarchical cluster analysis (MEGA clustering; McDermott, 1998) was employed as a second technique of capturing important variation in prevalence patterns using neighborhood types.

Prior to data reduction, ancillary analyses were conducted to examine bivariate relationships among the variables contained in the KIDS and NIS databases, since multicollinearity is often a problem with data from single cities (Duncan \& Raudenbush, 2001). The issue of redundancy was explored through a series of analyses, at which point several variables were excluded, either on statistical grounds or because they did not seem to be the most relevant for defining neighborhood context (e.g., "properties with taxes sold to lien"). With respect to exclusion on statistical grounds, we expelled variables that seemed to represent echoes of a preceding causal event. For example, gas shut off, water shut off, and abandoned property were all highly collinear with fires on property. Since fires on property, presumably, was the preceding causal reason for gas and water to be shut off and then property to be subsequently 
abandoned in many cases, we chose to retain "fires on property" for multivariate analyses.

The existence of latent neighborhood dimensions among the 10 remaining variables was explored through a series of common factor analyses, with squared multiple correlations used as initial communality estimates. Common factor analysis (CFA) was chosen over principal components analysis, because it looks only at the reliable variance associated with a group of variables and yields unbiased loadings with smaller standard errors (Snook \& Gorsuch, 1989). Analyses were conducted, rotating from one to eight factors using both orthogonal (varimax) and oblique (promax, where $k=2-6$ ) rotational methods. Multiple criteria were applied to determine the most reliable neighborhood dimensions. Criteria specified that the most viable factor structure should: (a) satisfy tests for the number of factors [e.g., Cattell's scree test (1966) and parallel analysis (Horn, 1965)]; (b) yield reasonable internal consistency (i.e., alpha coefficients $\geq .70$; Kline, 1993); (c) retain at least three variables per factor with salient loadings, where loadings $>.40$ are considered salient (Fabrigar, Wegener, MacCallum, \& Strahan, 1999); (d) hold simple structure via hyperplane count (i.e., simple structure occurs when the count of near-zero entries in the factor pattern matrices is highest, indicating maximum separation of factors; see Yaets, 1987 and Hakstian, 1971); and (e) be psychologically meaningful (Wood, Tataryn, \& Gorsuch, 1996). To further test the integrity of the final factor solution, the specificity of each factor was calculated and compared to the error variance, ensuring that the reliable and uniquely interpretable variance associated with each factor was higher than that attributable to error.

The utility of racial composition and property structure variables was addressed through the development of a neighborhood typology applied to describe meaningful subsets of block groups (Spencer et al., 1997). Cluster analysis was chosen to examine the prevalence patterns among neighborhood racial and structural composition variables. The 1,801 profiles associated with the corresponding block groups were submitted to multistage, hierarchical cluster analysis with replications and relocation (McDermott, 1998). The primary goal was to determine whether a meaningful typology of distinct neighborhood racial composition and property structure composition could be resolved.

Ward's (1963) minimum-variance procedure was chosen to meet the research goals, because there is ample evidence from Monte Carlo studies that when full coverage is required, Ward's method best recovers known typological structure (Kuiper \& Fisher, 1975; Mojena, 1977) and outperforms other methods in reducing overlap (Bayne, Beauchamp, Begovich, \& Kane, 1980; McDermott, 1995). Separate three-stage clustering processes were applied for both racial composition and structural property data. For each, the 1,801 profiles were first randomly assigned to nine mutually exclusive samples, and Ward's method was applied independently for the profiles comprising each sample. Then, for each sample, the ideal number of clusters was determined by: (1) an atypical decrease in overall between-cluster variance $\left(r^{2}\right)$ and increase in within-cluster variance (Ward, 1963) and (2) simultaneous elevation of the psuedo- $F$ statistic (Calinski \& Harabasz, 1974) over the psuedo- $t^{2}$ statistic (Duda \& Hart, 1973). (Note: Psuedo $F$ indicates separation among all clusters at the current step, whereas pseudo $t^{2}$ indicates separation of the two clusters immediately joined at the current step.)

Clusters derived from the nine independent firststage analyses were pooled and subjected to secondstage clustering. Specifically, a similarity matrix was constructed to impart full first-stage history (cluster mean-profiles, radial and dispersion statistics, and within-cluster profile frequency), and Ward's method was reapplied. Since agglomerative clustering provides no natural mechanism to relocate retrospectively misplaced profiles, third-stage clustering applied divisive $k$-means iteration (as advised by Scheibler \& Schneider, 1985) to relocate misplaced profiles. Selection criteria for second- and third-stage clustering were identical to those in first-stage clustering, and stopping rules were applied to ensure that each final cluster had a 100 percent replication rate as verified by absorption of the first stage-cluster into the same second- and third-stage cluster (as per Overall and Magee, 1992).

\section{Relations between latent neighborhood dimensions and types and kindergarten outcomes}

Simultaneous multiple regression analyses were conducted to determine the relations between empirically defined neighborhood variables and kindergarten children's performance outcomes. ${ }^{4}$

\footnotetext{
4 The use of multi-level regression analyses was precluded because over $60 \%$ of the block groups contained only 1 or 2 children $(50 \%$ of which contained only 1 child per block group).
} 


\section{Results}

\section{Latent neighborhood dimensions}

Factor analytic and cluster analytic data reduction techniques were employed with block-group level variables in order to define empirically "neighborhood" while accounting for collinearity among variables (McDermott, McWayne, Fantuzzo, \& Culhane, 2003). A series of exploratory common factor analyses indicated the model retaining two oblique (promaxian) dimensions met all stated criteria. Two factors were found to represent distinct dimensions of neighborhood context: Social Stress and Structural Danger (Cronbach's alpha $=.81$ and .85 , respectively). Table 2 presents the variables and factor loadings for each factor. Neighborhoods with a high score on the Social Stress dimension demonstrate elevated rates of truancy, child poverty, teen births, delinquent and dependent out of home placements, and substantiated abuse and neglect cases. Elevated scores on the Structural Danger dimension indicate neighborhoods with a high density of dangerous properties, incidences of residence fires, and lead levels that exceed maximal allowances. The specific and error variance associated with each neighborhood dimension supported the integrity of the twofactor oblique solution. Table 3 presents the factor intercorrelations and the variance components for each dimension.

Hierarchical cluster analyses resolved four distinct neighborhood types based on racial composition variables. Neighborhoods within this urban center were described as consisting of: (1) primarily African-American residents; (2) primarily Caucasian residents; (3) Mixed African-American and Caucasian residents; or, (4) primarily Hispanic, with African American and some Caucasian residents. Six distinct neighborhood types were revealed based on property structure variables-those consisting of: (1) primarily row homes; (2) primarily row homes, with some unimproved properties; (3) primarily row homes and semi-detached properties with some apartments and hotels; (4) primarily unimproved land properties and row-homes with some property tax-exempt, and citygovernment owned properties; (5) primarily semidetached houses with some detached houses and apartments or hotels; or (6) primarily detached houses with some semi-detached houses. Tables 4 and 5 show the characteristic mean profile values for each type.
Table 2 Exploratory factor structure for neighborhood dimensions $\left(N=1,801^{\mathrm{a}}\right)$

\begin{tabular}{|c|c|c|c|}
\hline Variable & $\begin{array}{l}\text { Promax } \\
\text { loading }\end{array}$ & & Item-total $r$ \\
\hline $\begin{array}{l}\text { Factor 1: Social Stress } \\
\qquad(\alpha=.85)\end{array}$ & Factor 1 & Factor 2 & \\
\hline $\begin{array}{l}\text { Truant children and } \\
\text { youths }\end{array}$ & .96 & -.09 & .80 \\
\hline Children in poverty & .72 & .09 & .71 \\
\hline Teen births & .70 & -.01 & .63 \\
\hline $\begin{array}{l}\text { Delinquent out } \\
\text { of home placements }\end{array}$ & .58 & .09 & .59 \\
\hline $\begin{array}{l}\text { Substantiated } \\
\text { abuse cases }\end{array}$ & .56 & -.16 & .40 \\
\hline $\begin{array}{l}\text { Substantiated } \\
\text { neglect cases }\end{array}$ & .48 & .06 & .49 \\
\hline $\begin{array}{l}\text { Dependent out } \\
\text { of home placements }\end{array}$ & .46 & .29 & .64 \\
\hline \multicolumn{4}{|l|}{$\begin{array}{l}\text { Factor 2: Structural } \\
\text { Danger }(\alpha=.81)\end{array}$} \\
\hline Dangerous property & -.26 & .95 & .69 \\
\hline Fires on property & .09 & .68 & .65 \\
\hline High lead & .23 & .57 & .63 \\
\hline
\end{tabular}

Note. Factor loadings in boldface type represent salient loadings on the respective factor. For convenience of presentation, variable wording has been abbreviated. Individual variables presented underneath the two factors represent counts of that particular phenomenon within a block group. Therefore, standardized scores for a given block group on each of the factors indicates the level of that dimension for the geographic area

a 1,801 denotes the number of block groups within the city used for factor analyses

b Entries are derived from a promaxian oblique rotation at $k=5$ with the varimax structure matrix serving as the initial orthogonal solution

\section{Relations between latent neighborhood dimensions and types and kindergarten outcomes}

Simultaneous multiple regression analyses explored the presence of significant associations between neighborhood dimensions and child outcomes. First, teacher ratings of children's language arts and mathematics performance were regressed separately on neighborhood types and factors. Next, both types and factors were included in a simultaneous model along with child demographic variables.

Initial regression analyses showed that neighborhood dimensions accounted for small but statistically significant proportions of variance in the dependent variables of language arts and mathematics performance in kindergarten. Together, the Social Stress and Structural Danger factors accounted for $3.0 \%$ and $3.4 \%$ of the variance in mathematics and language arts performance, respectively $(F[2,4961]=76.91$, 
Table 3 Intercorrelation and the common, reliable, specific, and error variance of dimensions

\begin{tabular}{|c|c|c|c|c|c|}
\hline \multirow[t]{2}{*}{ Dimension } & \multirow{2}{*}{$\frac{\text { Correlation }}{\text { Social Stress }}$} & \multicolumn{4}{|c|}{ Variance partitioning } \\
\hline & & Communality $^{\mathrm{a}}$ & Reliability & Specificity $^{\mathrm{b}}$ & Error $^{\mathrm{c}}$ \\
\hline Structural Danger & .73 & .46 & .81 & .35 & .19 \\
\hline Social Stress & & .46 & .85 & .39 & .15 \\
\hline
\end{tabular}

a Communality reflects the total proportion of common variance conveyed by a dimension

b Specificity indicates the proportion of variance that is both reliable and unique to a particular dimension. Specificity is calculated by subtracting communality for a dimension from its reliability coefficient

${ }^{c}$ Specificity values for the neighborhood dimensions did not exceed their error variance (where error variance $=1-$ reliability), and therefore specific variance is greater than that attributable to error

$p<.0001 ; F[2,4916]=87.37, p<.0001)$. Children who resided in block groups evidencing higher levels of Social Stress and Structural Danger demonstrated lower levels of performance in mathematics and language arts. Table 6 presents results from this regression analysis.

Regression analyses with the typological dimensions of neighborhood also accounted for small but statistically significant amounts of variance in the criterion measures of kindergarten performance $(2.0 \%$ and $3.2 \%$ for Racial Composition types; $1.0 \%$ and $1.4 \%$ for Property Structure types). The overall model involving Racial Composition revealed that compared with children living in primarily Caucasian neighborhoods, children living in primarily African American (Type 1), mixed African American and Caucasian (Type 3), and primarily Hispanic, with mixed African American and Caucasian (Type 4) neighborhoods demonstrated lower levels of performance on mathematics and language arts criterion measures $(F[3,4960]=55.42, p<.0001 ; F[2$, $4915]=33.79, p<.0001)$. See Table 7 for the complete results. Differential relations were found to exist between Property Structure Composition and children's performance. With respect to mathematics performance ratings, when compared with children living in neighborhoods comprised primarily of row homes, children in neighborhoods where undeveloped properties existed had lower performance ratings. Conversely, children living in neighborhoods primarily comprised of semidetached homes or single homes had higher performance ratings in mathematics, when compared with children who resided in neighborhoods primarily comprised of row homes (overall model- $F$ [5, 4958] $=13.67, p<.0001)$. This second finding was also confirmed for language arts performance; children in neighborhoods with predominantly semi-detached or single homes showed higher levels of performance than children living in neighborhoods comprised primarily of row homes $(F[5,4913]=10.25, p<.0001)$. Table 8 reports regression results for property structure types and children's performance outcomes.
A final simultaneous regression analysis was conducted with all four neighborhood constructs and child demographic variables. When child age, sex, and race were entered into the simultaneous model as control variables, statistically significant associations between neighborhood variables and children's academic outcomes remained (for language arts: $F[17,4890]=$ $22.01, p<.0001$; for mathematics: $F[17,4935]=22.02$, $p<.0001)$. However, standardized beta coefficients for the neighborhood variables in this final model generally decreased when compared with the earlier models. For both language arts and mathematics, the full models accounted for $7.1 \%$ of the total variance in the dependent variables. Table 9 presents the complete results based on the final regression models.

\section{Discussion}

This study represents the first population-based examination of administrative data at the block group level for an early childhood cohort. Neighborhood researchers have recommended this level of aggregation because it more closely represents actual neighborhoods within which children reside (Burton et al., 1997). Census tracts, which encapsulate as many as 8,000 residents, have been criticized as being too broad to capture unique variation in individual neighborhoods. Block groups, which typically encompass 600-3,000 residents, are likely to represent neighborhoods in large cities more accurately (Burton et al., 1997). Furthermore, this study aimed to consider multiple neighborhood influences by using administrative data collected from municipal agencies serving children and youth. There are several benefits to this approach. Given that municipal data are collected on an on-going basis, as compared with decennial census data, they can more accurately reflect the conditions of neighborhoods that are proximal to current child outcomes (Hillier \& Culhane, 2005). Too often, local policy-makers must apply outdated information from the decennial census to inform policy 


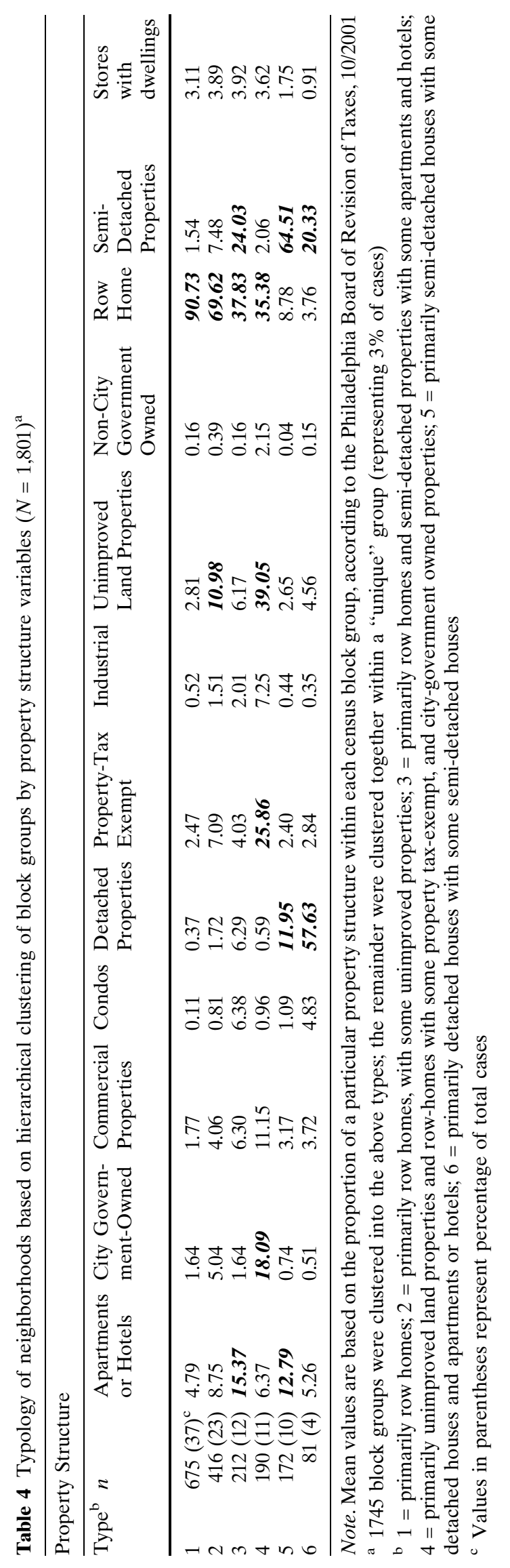


Table 5 Typology of neighborhoods based on hierarchical clustering of block groups by racial composition variables $(N=1,801)^{\mathrm{a}}$

\begin{tabular}{lllllll}
\hline \multicolumn{2}{l}{ Racial Group $^{2}$} & & & & & \\
\hline Type $^{\text {b }} n$ & $\begin{array}{l}\text { African- } \\
\text { American }\end{array}$ & Caucasian & Hispanic & Asian & Other \\
\hline 1 & $711(40)$ & $\mathbf{6 6 6 . 1 9}$ & 23.26 & 14.46 & 6.64 & 1.00 \\
2 & $640(36)$ & 62.78 & $\mathbf{8 3 2 . 5 6}$ & 49.74 & 46.63 & 1.81 \\
3 & $274(15)$ & $\mathbf{3 7 0 . 8 2}$ & $\mathbf{2 8 5 . 8 9}$ & 77.76 & 76.75 & 2.57 \\
4 & $121(7)$ & $\mathbf{1 9 3 . 2 7}$ & 84.85 & $\mathbf{4 9 1 . 7 8}$ & 25.17 & 1.73 \\
\hline
\end{tabular}

Note. Mean values are based on raw counts within each census block group, according to the 2000 U.S. Census

a 1746 block groups were clustered into the above types; the remainder were clustered together within a "unique" group (representing 3\% of total cases)

b 1 = primarily African-American residents; 2 = primarily Caucasian residents; 3 = Mixed African-American and Caucasian residents; 4 = primarily Hispanic, with African American and some Caucasian residents

${ }^{c}$ Values in parentheses represent percentage of total cases

decisions; administrative data allow for a more timely and responsive policy-making process. This study demonstrates that administrative data available at the block group level have the potential to provide a level of information concerning single cities, near commensurate with that provided by studies utilizing U.S. Census tract-level data with nationally representative samples.

In this study, common factor analyses and multistage, hierarchical cluster analyses yielded two dimensions and two typologies of neighborhood context: Structural Danger, Social Stress, Racial Composition, and Property Structure Composition. Structural Danger and Social Stress variables were formed using municipal, administrative data from several agencies serving this large, northeastern city. Racial Composition and Property Structure Composition variables

Table 6 Variation in children's mathematics and language arts performance ratings by social stress and structural danger dimensions

\begin{tabular}{lll}
\hline Explanatory Variable & \multicolumn{2}{l}{ Criterion Variable } \\
\cline { 2 - 3 } & $\begin{array}{l}\text { Language } \\
\text { Arts }\end{array}$ & Mathematics \\
\hline Neighborhood Structural & $-7.5^{* * * *}$ & $-7.0^{* * *}$ \\
$\quad$ Danger & & $-11.7^{\mathrm{a} * * *}$ \\
Neighborhood Social Stress & $-12.3^{* * *}$ & $3.0^{* * *}$ \\
Model $R^{2}(\%)$ & $3.4^{* * * *}$ & $(4,963)$ \\
$(N)$ & $(4,918)$ & \\
\hline
\end{tabular}

Note. $* p<.01, * * p<.001, * * * p<.0001$

a Values represent standardized $\beta$ coefficients (\%)
Table 7 Variation in children's mathematics and language arts performance ratings by racial composition type

\begin{tabular}{lll}
\hline $\begin{array}{l}\text { Explanatory Variable } \\
\text { Neighborhood }\end{array}$ & \multicolumn{2}{l}{ Criterion Variable } \\
\cline { 2 - 3 } Racial Composition Type & $\begin{array}{l}\text { Language } \\
\text { Arts }\end{array}$ & Mathematics \\
\hline Primarily African-American $^{\mathrm{a}}$ & $-9.4^{* * * \mathrm{~b}}$ & $-10.0^{* * *}$ \\
$\begin{array}{l}\text { Mixed African-American \& } \\
\quad \text { Caucasian }\end{array}$ & $-6.6^{* * *}$ & $-4.6^{*}$ \\
$\begin{array}{l}\text { Primarily Hispanic w/African } \\
\quad \text { American \& Caucasian }\end{array}$ & $-16.5^{* * * *}$ & $-19.8^{* * *}$ \\
$\begin{array}{l}\text { Model } R^{2}(\%) \\
(N)\end{array}$ & $2.0^{* * *}$ & $3.2^{* * *}$ \\
\hline
\end{tabular}

Note. $* p<.01, * * p<.001, * * * p<.0001$

a Primarily Caucasian neighborhoods served as the reference group for these analyses

b Values represent standardized $\beta$ coefficients (\%).

were formed using both U. S. Census and municipal information. All four second-order variables reflect salient aspects of the social and built environment.

The racial composition and social stress variables reflect social aspects of children's neighborhoods. Social characteristics are generally considered to be more proximate influences than the physical or structural aspects of neighborhood (Sampson \& Morenoff, 1997), although the two have been found to be highly related (Sampson \& Raudenbush, 1999). The racial composition variable formed in this study allowed for a descriptive look at racial prevalence patterns within neighborhoods comprising this urban center. Using a hierarchical clustering technique (McDermott, 1998),

Table 8 Variation in children's mathematics and language arts performance ratings by property structure types

\begin{tabular}{lll}
\hline Explanatory Variable & \multicolumn{2}{l}{ Criterion Variable } \\
\cline { 2 - 3 } $\begin{array}{l}\text { Neighborhood Property } \\
\text { Structure Type }\end{array}$ & $\begin{array}{l}\text { Language } \\
\text { Arts }\end{array}$ & Mathematics \\
\hline $\begin{array}{l}\text { Primarily row homes with } \\
\text { undeveloped properties }\end{array}$ & $2.1^{\mathrm{b}}$ & -0.6 \\
$\begin{array}{l}\text { Primarily row homes and semi- } \\
\text { detached w/apts \& hotels }\end{array}$ & $6.2^{* * * *}$ & $6.1^{* * * *}$ \\
$\begin{array}{l}\text { Primarily row homes } \\
\quad \text { w/undeveloped \& exempt } \\
\text { properties }\end{array}$ & 0.3 & $-4.2^{* *}$ \\
$\begin{array}{l}\text { Primarily semi-detached } \\
\quad \text { w/detached, apts, \& hotels }\end{array}$ & $6.2^{* * * *}$ & $7.1^{* * * *}$ \\
$\begin{array}{l}\text { Primarily detached homes } \\
\text { w/semi-detached }\end{array}$ & $6.7^{* * *}$ & $5.6^{* * * *}$ \\
$\begin{array}{l}\text { Model } R^{2}(\%) \\
(N)\end{array}$ & $1.0^{* * * *}$ & $1.4^{* * * *}$ \\
& $(4,918)$ & $(4,963)$
\end{tabular}

Note. $* p<.01, * * p<.001, * * * p<.0001$

a Neighborhoods comprised of primarily row homes served as the reference group for these analyses

b Values represent standardized $\beta$ coefficients (\%) 
Table 9 Variation in children's mathematics and language arts performance ratings, final model

\begin{tabular}{|c|c|c|}
\hline \multirow[t]{2}{*}{ Explanatory Variable } & \multicolumn{2}{|c|}{ Criterion Variable } \\
\hline & $\begin{array}{l}\text { Language } \\
\text { Arts }^{\text {a }}\end{array}$ & Mathematics \\
\hline Child age & $11.5^{* * *}$ & $13.1 * * *$ \\
\hline $\begin{array}{l}\text { Child sex (males compared to } \\
\text { females) }\end{array}$ & $-9.4 * * *$ & $-5.0 * *$ \\
\hline \multicolumn{3}{|l|}{ Child race (compared to Caucasian) } \\
\hline African American & $-10.7 * * *$ & $-9.7 * * *$ \\
\hline Hispanic & $-14.0 * * *$ & $-12.3 * * *$ \\
\hline Other & $-6.6 * * *$ & $-4.1 * *$ \\
\hline Neighborhood Structural Danger & $-8.3^{* * *}$ & -4.0 \\
\hline Neighborhood Social Stress & $-7.1 * * *$ & $-5.8^{* *}$ \\
\hline \multicolumn{3}{|l|}{ Neighborhood Racial Composition ${ }^{\mathrm{b}}$} \\
\hline Primarily African-American & 4.9 & 1.0 \\
\hline $\begin{array}{l}\text { Mixed African-American \& } \\
\text { Caucasian }\end{array}$ & 0.0 & 1.0 \\
\hline $\begin{array}{l}\text { Primarily Hispanic w/African } \\
\text { American \& Caucasian }\end{array}$ & 1.0 & $-6.4 * *$ \\
\hline \multicolumn{3}{|l|}{ Neighborhood Property Structure ${ }^{c}$} \\
\hline $\begin{array}{l}\text { Primarily row homes with } \\
\text { undeveloped properties }\end{array}$ & $3.1 *$ & -0.0 \\
\hline $\begin{array}{l}\text { Primarily row homes and semi- } \\
\text { detached w/apts \& hotels }\end{array}$ & $3.9 * *$ & $3.5^{*}$ \\
\hline $\begin{array}{l}\text { Primarily row homes w/ } \\
\text { undeveloped \& exempt properties }\end{array}$ & 2.2 & -1.2 \\
\hline $\begin{array}{l}\text { Primarily semi-detached w/ } \\
\text { detached, apts, \& hotels }\end{array}$ & 2.0 & $3.0^{*}$ \\
\hline $\begin{array}{l}\text { Primarily detached homes w/semi- } \\
\text { detached }\end{array}$ & $4.6^{* *}$ & $4.0^{* *}$ \\
\hline Final Model $R^{2}(\%)$ & $7.1 * * *$ & $7.1 * * *$ \\
\hline$(N)$ & $(4,917)$ & $(4,962)$ \\
\hline
\end{tabular}

Note. $* p<.05, * * p<.01, * * * p<.0001$

a Values represent standardized $\beta$ coefficients (\%)

b Primarily Caucasian neighborhoods served as the reference group for these analyses

${ }^{c}$ Neighborhoods comprised of primarily row homes served as the reference group for these analyses

neighborhoods (as defined by block group) most similar to each other with respect to the racial identity of residents were revealed. Two racial composition types represented the majority of block groups within this northeastern city: neighborhoods with primarily AfricanAmerican residents (40\% of total block groups) and neighborhoods comprised of primarily Caucasian residents (36\% of total block groups).

The neighborhood social stress variable that emerged in this study reflects the first attempt to date to employ administrative data from numerous municipal agencies to define aspects of the social neighborhood environment. Given the nature of the administrative data collected by agencies serving children and youth across the city, this dimension reflected the level of stressful social circumstances evident within an area. Neighborhoods receiving a high score on this dimension evidenced high counts of children living in poverty, teen births, delinquent and dependent out of home placements, substantiated abuse and neglect cases, and K-12 truancy. The particular variables comprising this dimension can be thought of as reflecting the level of social disorganization in a given community, as discussed by Wilson (1987), and one could hypothesize how these variables might have import for child development. For example, in neighborhoods with a high rate of truancy among children and youth, young children are disproportionately exposed to behaviors that might influence their aspirations about schooling. Abuse, neglect and dependent and delinquent out of home placements reflect a disorganization of family and may also reflect the limited availability of social networks upon which parents of young children can rely. The prevalence of social stress within a neighborhood may also be related to the issue of collective socialization-the level of monitoring, supervising, and role modeling within the larger neighborhood and community for children (Jencks \& Mayer, 1990). Neighborhoods high on this measure of social stress could plausibly be characterized as having low collective socialization, where children are less likely to experience the collective support of adults at a community level. However, these links will need to be tested in future research.

In this study, physical characteristics of neighborhood were defined by property structure types and a structural danger dimension. The typology of property structure provided a descriptive look at the property composition of neighborhoods (similar to the racial composition variable above). Row homes represented the predominant property structure in this urban center. The Structural Danger dimension reflected something about the physical neighborhood environment. A block group with a high score on this dimension had a disproportionate number of children at that address who tested high for lead content, properties that incurred fires within the last decade, and those that have been deemed "dangerous properties" by the city. Furstenberg and Hughes (1997) discuss how features such as the types and quality of housing provide boundaries of community development and social relationships. The local infrastructure of neighborhoods has been said to "provide the physical reality in which social life and individual development occurs" (p. 39). Thus, these physical characteristics may correspond to important constraints to social relationships that sustain optimal child development. Indeed, in the present study, neighborhood structural danger and social stress dimensions were highly correlated with one another $(r=.73)$. This strong relation is supported 
by other work within the field of sociology, where neighborhood structural characteristics were found to be strongly associated with social disorder (Sampson \& Raudenbush, 1999).

After defining empirically aspects of neighborhood using administrative data, we sought to examine the relations between these dimensions and children's early educational outcomes. Simultaneous multiple regression models revealed that neighborhood dimensions accounted for small but statistically significant proportions of the variation in children's mathematics and language arts performance ratings in kindergarten. When neighborhood dimensions were forced to compete with child demographic variables (age, sex, and race), associations remained between the Social Stress and Structural Danger variables and language arts, as well as between the Social Stress variable and mathematics. This study suggests that the concentration of social problems and structural quality at the neighborhood level may have a small but perceptible impact on individual children's academic performance. Therefore, when included with other salient variables, these social and physical quality indicators may have utility for future investigators seeking to test more complex models of neighborhood effects.

Some associations for neighborhood typologies were sustained in the final model. Although children's race accounted for significant proportions of variation in outcomes, there was one association that remained for racial composition of neighborhoods-children who lived in neighborhoods comprised primarily of Latino families, performed less well in mathematics than children who lived in neighborhoods comprised mainly of White families. However, for the most part, racial composition of the neighborhood did not seem to have a unique effect after controlling for child demographic and other neighborhood variables. This echoes findings reported in a review of empirical neighborhood studies (see Leventhal and Brooks-Gunn, 2000), where neighborhood effects were found to be more common for variables such as neighborhood SES than for racial/ ethnic heterogeneity. In the present study, there was some evidence indicating that certain property structure types had a very small, but unique effect; children who resided in neighborhoods comprised of semidetached and detached houses had higher performance ratings. As others have pointed out, these structural variables could actually be proxies for economic standing (Furstenberg \& Hughes, 1997).

Limitations of this study warrant discussion. First, we did not include measures of microsystem influences, such as the family and school. Though we believe that these more proximal systems vary with respect to larger contextual issues (Aber, Gephart, Brooks-Gunn, \& Connell, 1997), information on the characteristics of schools and families would certainly have explained additional variation in children's performance outcomes. Furthermore, given that suppression effects can occur when other salient variables are not included in the model (Duncan, Connell, \& Klebanov, 1997), it is plausible that neighborhood effects within this sample may be underestimated because important variables were omitted. Future studies will be necessary to examine potential moderating or mediating effects of neighborhood context using the empirically identified dimensions of this study.

Limitations also exist with respect to the neighborhood and child samples employed. This study is an empirical investigation of relations among variables within a single city. Replication and extension of this work is needed. Similar studies need to be conducted nationally to ascertain the implications of this approach. Cities may differ widely with respect to the social and physical conditions that might impact child development as well as with respect to the quality of administrative data collected, and overall findings will likely differ across municipalities. Moreover, the present study employed a large representative sample of urban public school children. The question still remains: Do the relationships reported here generalize to children attending parochial and other independent schools in the city? Perhaps type of schooling is a moderating variable.

In addition, it should be noted that only $7.1 \%$ of the variation in children's mathematics and language arts outcomes was accounted for by the child demographic and neighborhood variables together in this study. Again, this raises the question of the sufficiency of this even smaller level of aggregation to account for the effects of neighborhood influence on children's outcomes. Alternative measures of neighborhood should be included in future research. Most noticeably missing from the present study are those dimensions of neighborhood said to be reflective of social capital (Wilson, 1987) or institutional resources. We need studies that include both inhibitive and protective neighborhood factors to enhance our understanding of the transaction between distal contextual variables, the more proximal influences of family and school, and children's early outcomes (Aber \& Nieto, 2000).

Another promising approach for studying neighborhood effects on child development employs raster technology. Rather than relying on aggregations or summaries that impose an arbitrary spatial scale (such as census tracts and block groups) on relationships that may not reflect the actual scale of effect, raster kernel 
density yields the intensity of a particular variable (e.g., child poverty) at a given location, defined by where the child resides. Differential radii are defined around the child, placing the child at the center of their own neighborhood. Employing raster measures in examinations of context supports a child-centered approach to understanding environmental influences and has the potential to more fully exploit the richness of individual household and property-level administrative data (Hillier, Culhane, Smith, \& Tomlin, 2003).

In conclusion, we continue to struggle with the operationalization of neighborhood context. This study examined administrative data at the block group level in a single city and offers one possibility toward more refined measures for use in future research.

Acknowledgements This research was funded in part by the William Penn Foundation. Special thanks goes to Ronnie Bloom and her colleagues for their support, and to Ping Qin, Senior Database Administrator at the Cartographic Modeling Lab.

\section{References}

Aber, J. L., Gephart, M. A., Brooks-Gunn, J., \& Connell, J. P. (1997). Development in context: Implications for studying neighborhood effects. In: J. Brooks-Gunn, G. J. Duncan, \& J. L. Aber (Eds.), Neighborhood poverty: Vol. 1. Context and consequences for children, (pp. 44-61). New York: Russell Sage Foundation.

Aber, M. S., \& Nieto, M. (2000). Suggestions for the investigation of psychological wellness in the neighborhood context: Toward a pluralistic neighborhood theory. In: D. Cicchetti, J. Rappaport, I. Sandler, \& R. P. Weissberg (Eds.), The promotion of wellness in children and adolescents. Washington, DC: CWLA Press.

Bayne, R., Beauchamp, J., Begovich, C., \& Kane, V. (1980). Monte Carlo comparisons of selected clustering procedures. Pattern Recognition, 12, 51-62.

Bronfenbrenner, U. (1992). Ecological systems theory. In: R. Vasta (Ed.), Six theories of child development: Revised formulations and current issues, (pp. 187-249). Ithaca, NY: Cornell University Department of Human Development and Family Studies.

Brooks-Gunn J., Duncan G. J., Aber J. L. (Eds.) (1997). Neighborhood poverty: Volume II: Policy implications in studying neighborhoods. New York, NY: Russell Sage Foundation.

Brooks-Gunn, J., Duncan, G. J., Klebanov, P. K., \& Sealand, N. (1993). Do neighborhoods influence child and adolescent development? American Journal of Sociology, 99(2), 353395.

Burton, L. M., Price-Spratlen, T., \& Spencer, M. B (1997). On ways of thinking about measuring neighborhoods: Implications for studying context and developmental outcomes for children. In: J. Brooks-Gunn, G. J. Duncan, \& J. L. Aber (Eds.), Neighborhood poverty: Vol. 2. Policy implications in studying neighborhoods, (pp. 23-47). New York: Russell Sage Foundation.

Calinski, T., \& Harabasz, J. (1974). A dendrite method for cluster analysis. Communications in Statistics, 3, 1-27.
Cattell, R. B. (1966). The scree test for the number of factors. Multivariate Behavioral Research, 1, 245-276.

Chase-Lansdale, P. L., Gordon, R. A., Brooks-Gunn, J., \& Klebanov, P. K. (1997). Neighborhood and family influences on the intellectual ad behavioral competence of preschool and early school-age children. In: J. Brooks-Gunn, G. J. Duncan, \& J. L. Aber (Eds.), Neighborhood poverty: Vol. 1. Context and consequences for children, (pp. 79-118). New York: Russell Sage Foundation.

Chin, D., \& Kameoka, V. A. (2002). Psychosocial and contextual predictors of educational and occupational self-efficacy among Hispanic inner-city adolescents. Hispanic Journal of Behavioral Sciences, 24, 448-464.

Coulton, C. J., Korbin, J. E., \& Su, M. (1996). Measuring neighborhood context for young children in an urban area. American Journal of Community Psychology, 24(1), 5-32.

Coulton, C. J., Korbin, J. E., Su, M., \& Chow, J. (1995). Community level factors and child maltreatment rates. Child Development, 66, 1262-1276.

Duda, R. O., \& Hart, P. E. (1973). Pattern classification and scene analysis. New York: Wiley.

Duncan, G. J., \& Aber, J. L. (1997). Neighborhood models and measures. In: J. Brooks-Gunn, G. J. Duncan, \& J. L. Aber (Eds.), Neighborhood poverty: Vol. 1. Context and consequences for children, (pp. 62-78). New York: Russell Sage Foundation.

Duncan, G. J., Connell, J. P., \& Klebanov, P. K. (1997). Conceptual and methodological issues in estimating causal effects of neighborhoods and family conditions on individual development. In: J. Brooks-Gunn, G. J. Duncan, \& J. L. Aber (Eds.), Neighborhood poverty: Vol. 1. Context and consequences for children, (pp. 219-250). New York: Russell Sage Foundation.

Duncan, T. E., Duncan, S. C., Okut, H., Strycker, L. A., \& Hix-Small, H. (2003). A multilevel contextual model of neighborhood collective efficacy. American Journal of Community Psychology, 3, 245-252.

Duncan, G. J., \& Raudenbush, S. W. (2001). Getting context right in quantitative studies of child development. In: A. Thornton (Ed.), The well-being of children and families: Research and data needs, (pp. 356-383). Ann Arbor, MI: The University of Michigan Press.

Fabrigar, L. R., Wegener, D. T., MacCallum, R. C., \& Strahan, E. J. (1999). Evaluating the use of exploratory factor analysis in psychological research. Psychological Methods, 4,272

Farver, J. M., Natera, L. X., \& Frosch, D. L. (1999). Effects of community violence on inner-city preschoolers and their families. Journal of Applied Developmental Psychology, 20(1), 143-158.

Furstenberg, F. F. (1993). How families manage risk and opportunity in dangerous neighborhoods. In: W. J. Wilson (Ed.), Sociology and the public agenda. Newbury Park, CA: Sage.

Furstenberg, F. F., \& Hughes, M. E. (1997). The influence of neighborhoods on children's development: A theoretical perspective and a research agenda. In: J. Brooks-Gunn, G. J. Duncan, \& J. L. Aber (Eds.), Neighborhood poverty: Vol. 2. Policy implications in studying neighborhoods, (pp. 23-47). New York: Russell Sage Foundation.

Hakstian, A. R. (1971). A comparative evaluation of several prominent methods of oblique factor transformation. Psychmetrika, 36, 175-193.

Hillier, A. E., \& Culhane, D. P. (2005). Integrating and distributing administrative data to support community change. In: M. Weil (Ed.), The Handbook of community 
practice, (pp. 647-658). Thousand Oaks, CA: Sage Publications.

Hillier, A., Culhane, D., Smith, T., \& Tomlin, C. D. (2003). Predicting housing abandonment with the Philadelphia Neighborhood Information System. Journal of Urban Affairs, 25, 91-105.

Horn, J. L. (1965). A rationale and test for the number of factors in factor analysis. Psychometrika, 30, 179-185.

Jencks, C., \& Mayer, S. (1990). The social consequences of growing up in a poor neighborhood. In: L. E. Lynn, \&M. F. H. McGeary (Eds.), Inner-city poverty in the United States. Washington, DC: National Academy Press.

Kline, P. (1993). The handbook of psychological testing. New York, NY: Routledge.

Kuiper, F., \& Fisher, L. (1975). A Monte Carlo comparison of six clustering procedures. Biometrics, 31, 777-783.

Leventhal, T., \& Brooks-Gunn, J. (2000). The neighborhoods they live in: The effects of neighborhood residence on child and adolescent outcomes. Psychological Bulletin, 126(2), 309-337.

Leventhal, T., \& Brooks-Gunn, J. (2003). Children and youth in neighborhood contexts. Current Directions in Psychological Science, 12, 27-31.

Lurie, N., Popkin, M., Dysken, M., Moscovice, I., \& Finch M. (1992). Accuracy of diagnosis of schizophrenia in Medicaid claims. Hospital and Community Psychiatry, 43(1), 69-71.

Luthar, S. S., Cicchetti, D., \& Becker, B. (2000). The construct of resilience: A critical evaluation and guidelines for future work. Child Development, 71(3), 543-562.

Martinez, M. L. (2000). Neighborhood context and the development of African American children. In: S. Bruchey (Ed.), Children of poverty: Studies on the effects of single parenthood, the feminization of poverty, and homelessness, (pp. 1-145). New York: Garland Publishing, Inc.

McDermott, P. A. (1995). Sex, race, class, and other demographics as explanations for children's ability and adjustment: A national appraisal. Journal of School Psychology, 33, 75-91.

McDermott, P. A. (1998). MEG: Megacluster analytic strategy for multistage hierarchical grouping with relocations and replications. Educational and Psychological Measurement, $58,677-686$.

McDermott, P. A., McWayne, C. M., Fantuzzo, J. W., \& Culhane, D. P. (2003). Defining neighborhood context empirically. Paper presented at the 74th Annual Meeting of the Eastern Psychological Association, Baltimore, MD.

Mojena, R. (1977). Hierarchical grouping methods and stopping rules: An evaluation. Computer Journal, 20, 359-363.

Overall, J. E., \& Magee, K. N. (1992). Replication as a rule for determining the number of clusters in hierarchical cluster analysis. Applied Psychological Measurement, 16, 119-128.
Rothbard, A.B., Schinner, A.P., Hadley, T.R., \& Rovi, J.I. (1990). Integration of mental health data on hospital and community services. Administration \& Policy in Mental Health, 18, 91-99.

Sampson R. J., \& Morenoff, J. (1997). Ecological perspectives on the neighborhood context of urban poverty: Past and present. In: J. Brooks-Gunn, G. J. Duncan, \& J. L. Aber (Eds.), Neighborhood poverty: Volume II: Policy implications in studying neighborhoods, (pp. 1-22). New York, NY: Russell Sage Foundation.

Sampson, R. J., Morenoff, J. D., \& Earls, F. (1999). Beyond social capital: Spatial dynamics of collective efficacy for children. American Sociological Review, 64, 633-660.

Sampson, R. J., \& Raudenbush, S. W. (1999). Systematic social observation of public spaces: A new look at disorder in urban neighborhoods. American Journal of Sociology, 105, 603-651.

Scheibler, D., \& Schneider, W. (1985). Monte Carlo tests of the accuracy of cluster analysis algorithms - A comparison of hierarchical and nonhierarchical methods. Multivariate Behavioral Research, 20, 283-304.

Snook, S. C., \& Gorsuch, R. L. (1989). Component analysis versus common factor analysis: A Monte Carlo study. Psychological Bulletin, 106, 148-154.

Spencer, M. B., McDermott, P. A., Burton, L. M., \& Kochman, T. J. (1997). An alternative approach to assessing neighborhood effects on early adolescent achievement and problem behavior. In: J. Brooks-Gunn, G. J. Duncan, \& J. L. Aber (Eds.), Neighborhood poverty: Vol. 2. Policy implications in studying neighborhoods, (pp. 23-47). New York: Russell Sage Foundation.

Ward, J. H. (1963). Hierarchical grouping to optimize an objective function. American Statistical Journal, 58, 236-244.

Wilson, W. J. (1987). The truly disadvantaged: The inner city, the underclass, and public policy. Chicago: University if Chicago Press.

Wood, J. M., Tataryn, D. J., \& Gorsuch, R. L. (1996). Effects of under- and overextraction on principal axis factor analysis with varimax rotation. Psychological Methods, 1, 354-365.

Yaets, A. (1987). Multivariate exploratory data analysis: A perspective on exploratory factor analysis. Albany, NY: State University of New York Press.

Zill, N., Moore, K. A., Smith, E. W., Stief, T., \& Coiro, M. J. (1995). The life circumstances and development of children in welfare families: A profile based on national survey data. In: L. P. Chase-Lansdale, \& J. Brooks-Gunn (Eds.), Escape from poverty: What makes a difference for children? (pp. 3859). New York: Cambridge University Press. 